\title{
温度变化驱动二氧化碳还原为甲醇
}

张跃 $^{1,2}$

1. 北京市新能源材料与技术重点实验室, 北京 100083 ;

2. 北京科技大学材料科学与工程学院, 北京 100083

E-mail: yuezhang@ustb.edu.cn

\section{Reduction of carbon dioxide to methanol driven by temperature-variation}

\author{
Yue Zhang, ${ }^{1,2}$ \\ ${ }^{1}$ Beijing Key Laboratory for Advanced Energy Materials and Technologies, Beijing 100083, China; \\ ${ }^{2}$ School of Materials Science and Engineering, University of Science and Technology Beijing, Beijing 100083, China \\ E-mail: yuezhang@ustb.edu.cn \\ doi: 10.1360/TB-2021-0236
}

数百年来, 化石燃料一直是人类活动和工业生产的主要 能源来源. 随着全球经济发展和对能源需求增加，二氧化碳 排放量日益增多，随之带来的如能源危机、全球气温升高和 海洋酸化问题困扰着人类. 如何能够显著降低环境中二氧化 碳并进行有效利用迫在眉睫 ${ }^{[1]}$. 通过还原技术将二氧化碳转 化为可利用的有机燃料不仅能够解决温室效应带来的问题, 还能够一定程度上缓解能源危机. 二氧化碳还原在光催化领 域和二氧化碳加氢反应中已经实现，但是由于产量较低或是 反应条件苛刻, 还无法应用于工业大规模生产.

温度变化是生活中的常见现象, 高效利用这种潜在能源 意义重大 ${ }^{[2,3]}$. 热释电效应是指材料的极化强度随温度变化而 表现出释放电荷的现象，宏观上是温度的变化使材料在两端 产生电压或者电流，是热释电体的一种自然物理效应. 热释 电效应被广泛的应用于辐射和非接触式温度测量、红外光 谱测量、红外摄像和工业自动控制中. 近年来, 热释电材料 在催化领域的研究被越来越多的报道, 热释电过程中产生的 自由电荷可参与到诸如有机染料降解、水分解制氢等催化 反应过程 ${ }^{[4,5]}$. 然而截至目前, 尚未有利用热释电材料从温度 变化中获取能量来进行二氧化碳还原的相关报道.

人们对铁电材料的催化性能研究已经有大概 70 年的历 史. 例如，铁电体极化产生的内建电场可以分离电子和空穴, 从而提高催化效率; 铁电极化可以影响分子从材料表面的吸 附和脱附等. 众所周知, 所有铁电材料都是热释电材料. 铇酸 铋是奥里维里斯(Aurivillius)化合物中最简单的一种, 具有较 好的铁电性质和热释电性质. 并且, 铇酸铋同时具有较大的
自发极化强度 $\left(P=50 \mu \mathrm{C} \mathrm{cm}^{-2}\right)$ 、较高的居里温度 $\left(T_{\mathrm{C}}=950^{\circ} \mathrm{C}\right)$ 以及较好的光催化性质 ${ }^{[6,7]}$. 此外, 铇酸铋由层状 $\left(\mathrm{Bi}_{2} \mathrm{O}_{2}\right)^{2+}$ 和 $\left(\mathrm{WO}_{4}\right)^{2-}$ 交替组成, 因而又具有较好的热稳定性和化学稳 定性.

基于此, 苏州大学邹贵付课题组近期在Nature Communications 发表了题为“Pyroelectric nanoplates for reduction of $\mathrm{CO}_{2}$ to methanol driven by temperature-variation”的文章 ${ }^{[8]}$. 该 工作利用热释电材料铇酸铋纳米片从温度变化中获取能量, 有效地将二氧化碳转化为甲醇. 该工作首先用水热法合成了 铇酸铋纳米片, 图1(a) (c)显示了所合成样品的结构表征. X 射线衍射(XRD)表征体现了其具有良好的结晶性; 扫描电子 显微镜(SEM)图片显示了合成的铇酸铋为片状结构; 原子分 辨高角环形暗场扫描透射电子显微镜(HAADF-STEM)进一 步通过微观显示了铇酸铋独特的层状结构. 催化实验结果显 示, 铇酸铋纳米片在 $15 \sim 70^{\circ} \mathrm{C}$ 温度区间经历 20 个循环后, 二氧 化碳转化甲醇效率为 $55 \mu \mathrm{mol} \mathrm{g}$. 密度泛函理论计算进一步 揭示了甲醇在铇酸铋表面的形成过程: 首先, 3 个氢离子与碳 结合, 且该过程是放热的, 比较容易进行; 接下来, 1 个碳氧单 键断裂, 生成 $\mathrm{CH}_{3} \mathrm{O}$ *和 1 个氧离子, 随后的 $\mathrm{H}$ 离子将被分离的 $\mathrm{O}$ 离子吸引, 直到形成 1 个 $\mathrm{H}_{2} \mathrm{O}$ 分子; 最后, 在 $\mathrm{CH}_{3} \mathrm{O}$ * 上再附着 1 个氢离子后, 生成甲醇 $\left(\mathrm{CH}_{3} \mathrm{OH}\right)$ 分子. 二氧化碳还原为甲醇 的相关反应机理如图 1(d)所示. 首先在温度恒定的情况下, 铇 酸铋纳米片的自发极化与表面束缚电荷保持平衡, 不会有电 荷的产生与转移. 当外界温度升高, 铇酸铋纳米片自发极化 变小，其内在自发极化与外界束缚电荷平衡被打破，产生的 

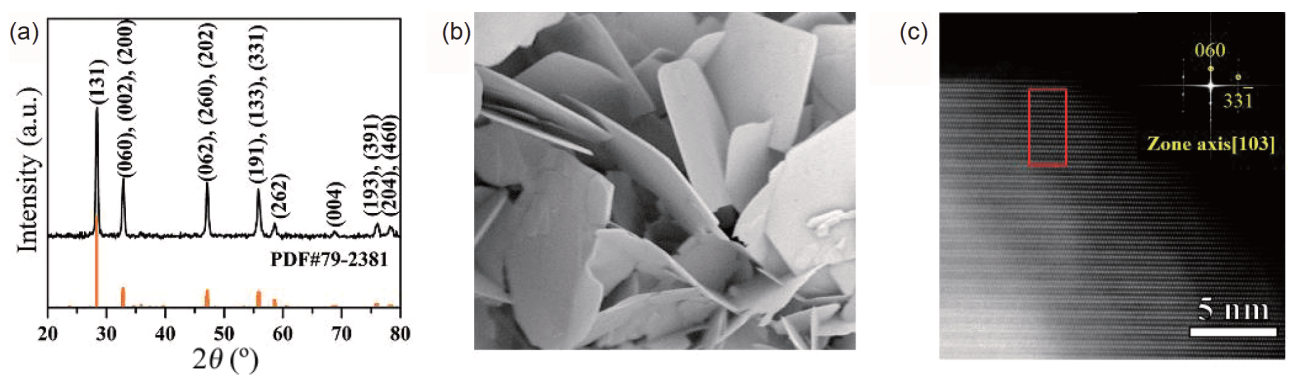

(d)
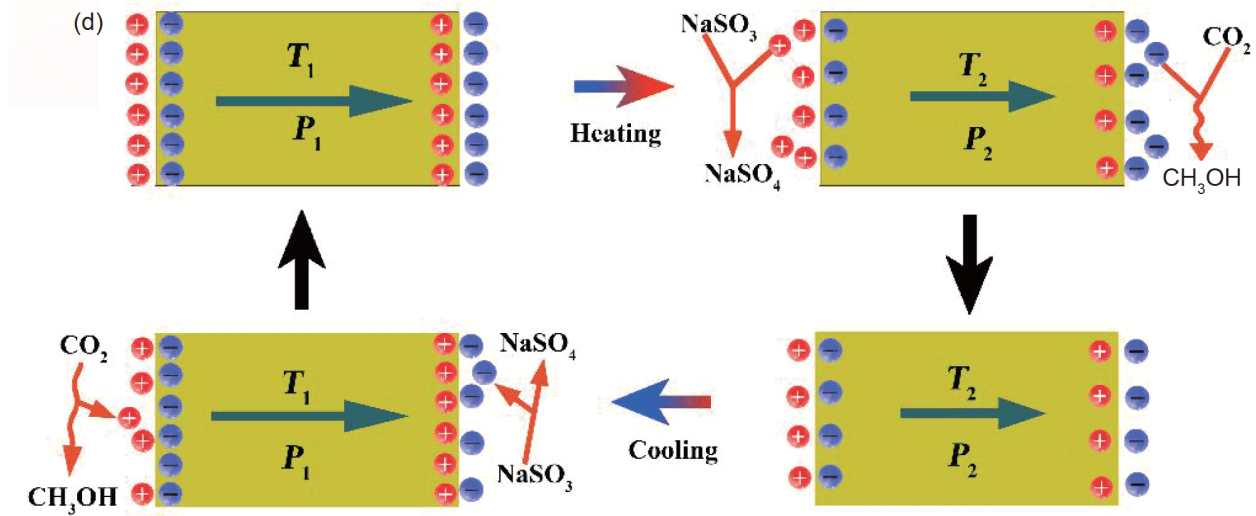

图 1 (网络版彩色)铇酸铋的结构表征. (a) XRD, (b) SEM图片, (c) 原子分辨HAADF-STEM图. (d) 热释电催化还原二氧化碳为甲醇机理示意图 ${ }^{[8]}$ Figure 1 (Color online) Structures of $\mathrm{Bi}_{2} \mathrm{WO}_{6}$ sample. (a) XRD pattern. (b) SEM photograph. (c) Aberration-Corrected HAADF-STEM image. (d) The mechanism of pyroelectric catalytic $\mathrm{CO}_{2}$ reduction induced by pyroelectric $\mathrm{Bi}_{2} \mathrm{WO}_{6}$ nanoplate ${ }^{[8]}$

自由电荷与吸附在铇酸铋纳米片表面的二氧化碳反应生成 甲醇. 温度升高到一定值保持不变时，自发极化与束缚电荷 重新保持平衡. 温度下降时，相反的电荷转移导致新的 二氧化碳还原过程，直到铇酸铋的自发极化与束缚电荷保持 平衡.

该工作采用热释电材料从温度变化中获取能量以实现
二氧化碳向甲醇转换，是一种高效、环保、经济的二氧化碳 还原方法，为利用自然界中温度变化进行甲醇生产提供了备 选技术途径．然而目前这种方法的转换效率还很低，且温度 大于我们日常生活环境的温度. 希望接下来通过催化剂的设 计或者光热联合催化，可以实现利用室温范围内的更高效率 的二氧化碳转化效率.

\section{参考文献}

1 Li M, Wang H, Luo W, et al. Heterogeneous single-atom catalysts for electrochemical $\mathrm{CO}_{2}$ reduction reaction. Adv Mater, 2020, $32: 2001848$

2 Lang S B, Muensit S. Review of some lesser-known applications of piezoelectric and pyroelectric polymers. Appl Phys A, 2006, 85: 125-134

3 Pandya S, Wilbur J, Kim J, et al. Pyroelectric energy conversion with large energy and power density in relaxor ferroelectric thin films. Nat Mater, 2018, 17: 432-438

$4 \mathrm{Wu}$ J, Mao W, Wu Z, et al. Strong pyro-catalysis of pyroelectric $\mathrm{BiFeO}_{3}$ nanoparticles under a room-temperature cold-hot alternation. Nanoscale, 2016, 8: 7343-7350

5 Xu X, Xiao L, Jia Y, et al. Pyro-catalytic hydrogen evolution by $\mathrm{Ba}_{0.7} \mathrm{Sr}_{0.3} \mathrm{TiO}_{3}$ nanoparticles: Harvesting cold-hot alternation energy near roomtemperature. Energy Environ Sci, 2018, 11: 2198-2207

6 Djani H, Hermet P, Ghosez P. First-principles characterization of the $P 2_{1} a b$ ferroelectric phase of Aurivillius $\mathrm{Bi}_{2} \mathrm{WO}_{6}$. J Phys $\mathrm{Chem} \mathrm{C}_{2} 2014,118$ : $13514-13524$

7 Liang L, Lei F, Gao S, et al. Single unit cell bismuth tungstate layers realizing robust solar $\mathrm{CO}_{2}$ reduction to methanol. Angew Chem Int Ed, 2015, 54: 13971-13974

8 Xiao L, Xu X, Jia Y, et al. Pyroelectric nanoplates for reduction of $\mathrm{CO}_{2}$ to methanol driven by temperature-variation. Nat Commun, 2021, 12: 318 